\title{
Sonidos de un Chile profundo. Hacia un análisis crítico del Archivo Sonoro de Música Tradicional Chilena en relación a la conformación del folclore en Chile
}

\section{Sounds from the Depth of Chile. Toward a Critical Analysis of the Sound Archive of Chilean Traditional Music as regards the establishing of Folklore in Chile}

\author{
por \\ Mariana León Villagra \\ Antropóloga Universidad de Chile, \\ Investigadora Adjunta de CEDIM. \\ marianaleonv@gmail.com \\ Ignacio Ramos Rodillo ${ }^{1}$ \\ Facultad de Filosofía y Humanidades, Universidad de Chile, \\ Investigador Adjunto de CEDIM. \\ heliotropismo@gmail.com
}

\begin{abstract}
Puesto que la música es el único lenguaje que posee los atributos contradictorios de ser un tiempo inteligible e intraducible, el creador musical es un ser comparable a las deidades, y la música es el misterio supremo de la ciencia humana.

Claude Lévi-Strauss, Mitológicas I, Lo crudo y lo cocido
\end{abstract}

La revisión del proceso de rescate patrimonial del Archivo Sonoro de Música Tradicional permite criticar los conceptos de patrimonio e identidad pertinentes, a la luz de la actual situación de las músicas

${ }^{1}$ Desde el año 2005 se desempeñan como investigadores adjuntos al Centro de Documentación e Investigación Musical (CEDIM) de la Facultad de Artes de la Universidad de Chile, a cargo del profesor Rodrigo Torres. 
locales y tradicionales en el contexto globalizado de las tecnologías digitales. Según esta perspectiva, es necesario recrear la historia del desarrollismo cultural chileno de la década de los 40 y de los 50 , mediante el análisis de la construcción de la identidad nacional bajo el concepto de folclore. Al poner en valor estas músicas y sonoridades tradicionales, fortalecemos la presencia de las identidades locales en la cultura chilena, destacando su importancia para una democratización real de las políticas culturales del estado.

Palabras Claves: Patrimonio cultural, Identidades, Músicas locales, Folclore, Archivo Sonoro de Música Tradicional Chilena, Universidad de Chile.

The process of rescueing from destruction the patrimonial legacy contained in the Sound Archive of Chilean Traditional Music serves as a basis for a critical review of the concepts of identity and patrimony within the current situation of traditional and local musics in the worldwide context of digital technologies. According to this perspective, it is necessary to review the history of the Chilean cultural development of the 40's and 50's, focusing on the construction of a national identity based on the concept of folklore. If the value of these traditional musics and sounds is brought to light it is possible to strengthen the presence of local identities in the Chilean culture, thus emphasizing their importance for cultural state policies aiming to be truly democratic.

Key words: Cultural heritage, Identities, Local musics, Folklore, Archive of Traditional Music in Sound, University of Chile.

\section{INTRODUCCIÓN}

La música es un fenómeno no meramente artístico, es expresión y sensibilidad de las personas, de los grupos; nos une, nos identifica y nos diferencia. Como amantes de la música y como cientistas sociales, pretendemos aquí exponer la importancia de las músicas y sonidos como manifestaciones socioculturales y como partes integrales de todo patrimonio cultural. Reseñaremos la experiencia del tratamiento patrimonial y puesta en valor de los registros sonoros del Archivo de Música Tradicional Chilena de la Universidad de Chile (en adelante AMTCh). A partir de esta experiencia, presentaremos las reflexiones e impresiones que se han generado en el transcurso del trabajo, en torno a la importancia de las músicas tradicionales para una lectura de contextos histórico-sociales, la conformación de identidades y respecto a las implicancias patrimoniales de estas músicas.

El artículo comprenderá una primera parte, que contextualiza la conformación del AMTCh, junto a un análisis histórico para entender acerca del tipo de registros que se abordan en el trabajo. En una segunda parte, describiremos la labor y el trabajo efectuado entre los años 2006 y 2007, para continuar con las reflexiones que se desprendieron de este proyecto, las que versan en dos ámbitos: tratamiento del patrimonio sonoro y problemática del patrimonio cultural.

Los proyectos de nación tradicionalmente se han caracterizado por obedecer a dos impulsos simultáneos. El primero, es el de adscripción al proyecto modernizador propio de Europa Occidental, en el que las ideas de soberanía popular y su expresión política en un estado-nacional fueron acompañadas de reformas económicas de tipo industrial. El segundo impulso, contrarrestando los efectos de dicha adscripción, es el que propende a reorganizar y destacar aquellos aspectos que eran sentidos como peculiarmente "propios" de la cultura autóctona, con lo que se preservaría una cierta identidad nacional. Este despliegue histórico se ha dado sin mayores diferencias entre nacionalismos. Por ende, al hablar culturalmente de éstos consideraremos dos 
tendencias fuertes que han determinado sus procesos particulares. Estas son el cosmopolitismo y el localismo ${ }^{2}$.

En Chile, la historia del ideal nacional moderno comprende un proceso de enorme relevancia. Su comienzo se produce aproximadamente en la década de 1920, para consagrarse a fines de los años 30 con la versión criolla del estado de bienestar, instaurado en base al programa desarrollista delineado por los gobiernos radicales. Sus consecuencias económicas y políticas, se demuestran por la acción productiva del estado empresario, por la solidez de la república y por la situación de aparente armonía entre los distintas facciones políticas -en general, todos involucrados en algún grado en el "proyecto país". Estas situación habría generado una sensación general de crecimiento y mejora. Chile calzaba en los parámetros de una república moderna, aparentemente superaba ya sus conflictos políticos, económicos y sociales, por lo que cundió el convencimiento sobre la unidad de su pueblo, expresada en la legitimidad de su estado. Indudablemente, la situación de aparente tranquilidad y compromiso social se desvaneció luego en la experiencia de la Unidad Popular, para desaparecer al fin tras el golpe militar de 1973.

En principio, la cultura que resultase de este proyecto nacional debía dar cuenta del progreso vivido. Además debía ser forzosamente una cultura que verdaderamente plasmara las situaciones de avance y estabilidad en que se vivía -o al menos, en las que se creía estar viviendo- justificándolas simbólica y discursivamente. En definitiva, debía ser una cultura al servicio de la moderna prosperidad del país y, al mismo tiempo, que también expresase y fortaleciese esa unidad espiritual. De esta forma, las perspectivas políticas descritas reflejaban la tendencia general para los países latinoamericanos, en los que se aplicaban modelos globales de desarrollo socio-económico que intervendrían irremediablemente las formas de vida tradicionales de parte importante de sus poblaciones. En nuestro caso, el estado de Chile incluyó dentro de su amplio programa la constitución de una institucionalidad cultural, cuyo epicentro fueron la educación escolar y principalmente la universitaria. En esta última dimensión la Universidad de Chile fue paradigmática, reuniendo en sí misma las tareas de investigación, docencia y extensión en todas las áreas que tuviesen relevancia nacional. Estas labores académicas aportaron a la concreción del ideal desarrollista, esto es alta cultura para hacer de Chile una nación al nivel de las más prósperas y desarrolladas del mundo, pero por sobre todo, para consolidar la unidad de su pueblo.

Esta modernización en la cultura, que convendría llamar política cultural oficial del Estado chileno, adquiría rasgos hegemónicos en el sentido que su labor sería, en lo futuro, clasificar y seleccionar todos los aspectos de lo nacional que fuesen representativos de su identidad. Dentro de esta línea, las culturas tradicionales del país cobraron la importancia que antes no tuvieron puesto que en ellas se conservaba la fibra más auténtica del "ser chileno". En consecuencia, con la inspiración modernista de la cultura oficial, la instalación de lo popular-tradicional dentro de este proyecto identitario fue realizada desde la universidad, mayoritariamente. Existieron antecedentes de estudios folclorológicos desde fines del siglo XIX ${ }^{3}$. No obstante, recién la

\footnotetext{
${ }^{2}$ Chatterjee 2000:128

${ }^{3}$ Ver, por ejemplo, el trabajo pionero del sabio alemán Rodolfo Lenz, Sobre la poesía popular impresa de Santiago de Chile. Contribución al folklore chileno, cuya investigación y escritura se desarrolló entre 1890 y 1895 , pero cuya presentación al público chileno sólo se hizo en 1919.
} 
oficialidad destinó una estructura permanente a esta materia a partir de la década de 1940, concretamente con la fundación del Instituto de Investigaciones FolklóricoMusicales de la Universidad de Chile. Este gesto marcaría el ingreso definitivo de las culturas tradicionales del país al ámbito de los estudios cultos, académicos, bajo la categoría de folclore.

El estudio del folclore musical chileno tuvo su base en una tarea de recopilación de registros de campo, a cargo de los investigadores de planta de dicha institución. Estos registros, junto a los de folcloristas y estudiosos independientes que donaron su material a la Universidad, en un gesto que dice mucho acerca del sentido patriótico de su trabajo, constituyeron el Archivo Sonoro al cual nos referimos. Dentro del grueso de recopiladores que engrosaron este acervo patrimonial se encuentran Manuel Dannemann, Héctor Pavez, Raquel Barros, Ercilia Moreno Cha, Violeta Parra, Carlos Lavín, Jorge Urrutia Blondel, Margot Loyola, María Ester Grebe, Leopoldo Castedo, por nombrar a los más conocidos. Dicha colección de cintas está compuesta por registros de músicas tradicionales en diversos contextos -sobre todo, en fiestas populares religiosas- entrevistas a cultores, y en menor grado, músicas indígenas y tradicional-urbanas, recogidos con regularidad desde la década de 1940 hasta 1970. A ello se agregan materiales donados durante la dictadura militar, hasta 1988 aproximadamente, los que cubren geográficamente desde el extremo norte de Chile hasta el Archipiélago de Chiloé. El AMTCh, por su doble procedencia, funcionó la mayor parte del tiempo como fuente primaria para el trabajo de especialistas e investigadores, los que en general expusieron sus resultados en las aulas y en publicaciones. Sirvió además como fuente de repertorios para los conjuntos y solistas intérpretes que se encargarían de difundir el folclore chileno al público desde los escenarios. Ambas áreas convergieron en la educación escolar, en la que, a modo de ejemplo, la enseñanza de bailes folclóricos -que todos hemos recibido- y particularmente la coreografía de estos, surgen de políticas educacionales sustentadas en este principio identitario.

\section{Experiencia del tratamiento sonoro: de las músicas locales frente a lo digital al trabajo patrimonial}

Este es en rasgos generales el contexto que dio su origen al AMTCh. Para efectos de su puesta en valor, se generó una premisa que para el equipo realizador fue fundamental. La música es una expresión humana, parte de la cultura y una motivación vital. Por ello hay que dar una valoración a las expresiones musicales y sonoras como parte de nuestro patrimonio cultural. Frente a un archivo sonoro de difícil acceso ${ }^{4}$, contenido en soportes obsoletos y en una peligrosa situación de deterioro material, es que a fines del año 2005 se conformó el equipo Atempo, compuesto por profesionales de las áreas de Musicología, Antropología, Historia, Sonido y Conservación

${ }^{4}$ El AMTCh en su totalidad está constituido por cintas reel, formato análogo actualmente obsoleto y que se haya sujeto a un proceso de degradación natural. Hace varios años que no se construyen maquinas reproductoras para este formato. Al ser muy pocas las que sobreviven, de no actuar rápidamente corremos el riesgo de perder la valiosísima información contenida en estas cintas, así como las de muchos otros archivos de estas características. Para el caso de este Archivo, esta situación ya ha sido mitigada. 
Audiovisual ${ }^{5}$, al alero del Centro de Documentación e Investigación (CEDIM). La principal meta fue darle accesibilidad a este archivo dentro del marco académico y contemplando luego su difusión a nivel general. Gracias a recursos obtenidos del Ministerio de Educación (Mineduc) por medio del Fondo de Desarrollo Institucional FDI- $2005^{6}$, se realizó el rescate de las cintas. Durante el año 2006, y sobre la base de estándares internacionales de tratamiento y conservación audiovisual, las cintas fueron restauradas y posteriormente traspasadas del original análogo a su actual soporte digital. Esta es la manera más adecuada de proteger el material, ya que al ser traspasada la información contenida, se asegura su preservación en formatos de alta densidad, los que permiten el transporte y duplicación del contenido junto a ulteriores procesamientos en distintos formatos?

A medida que avanzábamos en la etapa de digitalización, nos dimos cuenta de la importancia de dar a conocer este proyecto a un público más amplio. Fue así como en el año 2006 conseguimos recursos del Consejo Nacional de la Cultura y las Artes (CNCA) por medio del Fondo para el Fomento de la Música Nacional ${ }^{8}$, para la producción de un disco, el cual fue editado en torno a la idea de fiesta tradicional en Chile. La elección de este tópico permitió aunar una parte importante de la diversidad de expresiones musicales que se escuchan normalmente en las festividades populares del país, sean estas religiosas, profanas, indígenas o mestizas. Este trabajo de investigación y edición se materializó en el álbum Pueblo en fiesta. Músicas tradicionales de Chile, lanzado en abril de $2007^{9}$. La producción de este disco tuvo como fin dar a conocer el archivo al público general, y permitir en parte su tan ansiado acceso generalizado como una política particular de patrimonio. Podemos explicar esta política en función de dos hechos. En primer término, generar un documento sonoro que mantuviese la voz de los cultores y los sonidos ambientales, en una presentación que estuviera dirigida no sólo a los profesionales de las ciencias humanas y de la música, sino también a escolares, profesores y público de toda índole. En segundo término, darle accesibilidad gratuita mediante donaciones a instituciones educacionales y centros culturales de la Región Metropolitana ${ }^{10}$, sobre todo por medio de la entrega de

\footnotetext{
${ }^{5}$ El equipo Atempo estuvo compuesto por el etnomusicólogo Rodrigo Torres, los cientistas sociales Mariana León e Ignacio Ramos, los licenciados en sonido Alex Geell y Jorge Veliz, además del ingeniero en sonido Francisco Miranda, especialista en tratamiento de restauración y conservación audiovisual del Centro Tecnológico (CENTEC) de la Facultad de Artes.

${ }^{6}$ Proyecto del Fondo de Desarrollo Institucional-FDI 2005 del Mineduc, Rescate del Archivo Sonoro de Música Tradicional Universidad de Chile.

Cada versión digital de las cintas incluye su material gráfico (carátula, notas de campo, material institucional), el cual también ha sido digitalizado. El registro sonoro se ha conservado inicialmente en un master, formato de alta densidad que alberga toda la información -incluso el ruido y los errores originales de la grabación. Esto permite su posterior procesamiento y edición. En segundo lugar, la información es traspasada a formato WAV, el cual puede copiarse en un CD para reproducirse en un equipo casero. El uso público, tras la etapa de edición, será facilitado mediante formatos comprimidos, de preferencia mp3 u Ogg, a través del Catálogo Bello.

${ }^{8}$ Fondo para el Fomento de la Música Nacional 2006, Selección discográfica y difusión del Arcbivo Sonoro de Música Tradicional Chilena, Universidad de Chile (folio 200635382).

${ }^{9}$ Dannemann 2007:101-102.

${ }^{10}$ Estas comprenden a la Red de Bibliotecas de la Universidad de Chile, Museo Chileno de Arte Precolombino, Archivo de Literatura Oral y Tradiciones Populares de la Biblioteca Nacional, Biblioteca de Santiago, Centro de Documentación de Bienes Patrimoniales de la Dirección de Bibliotecas Archivos y Museos (Dibam) y el Museo de Arte Popular Americano (MAPA) de la Universidad de Chile.
} 
200 copias a la División de Bibliotecas Públicas, para su distribución a lo largo de Chile.

Nuestro trabajo responde a una valoración de las músicas locales y del patrimonio cultural sonoro frente a las nuevas situaciones que los afectan, específicamente bajo las condiciones en que se generan y transmiten actualmente las músicas a lo largo del mundo. Podemos decir que, como muchos otros fenómenos sociales, las músicas se han visto afectadas por los cambios causados por la globalización y por el auge de la tecnología digital. Según lo indica la musicóloga Ana Maria Ochoa en su análisis de la situación actual de las músicas locales, la relación entre las músicas y sus contextos/lugares originales cada vez se hace más difusa. Lo anterior, producto de los cambios tecnológicos más recientes, pues las mayores posibilidades de registrar y transportar sonidos digitalmente, como lo propone a su vez Steven Feld, propician su desvinculación geográfica y cultural, lo que es explicado por el autor mediante el concepto de "esquizofonia" final de ésta desvinculación, dadas "la total portabilidad, transportabilidad y transmutabilidad de cualquier y todos los ambientes sonoros" ${ }^{2}$. Este fenómeno ha tenido dos efectos fundamentales, la espectacularización de los sonidos y su intermedialidad ${ }^{13}$. Estos fenómenos han sido cruciales para el desarrollo contemporáneo de la música popular. Es el caso, por ejemplo, de la música electrónica, en la que los DJs son capaces de manipular y mezclar digitalmente registros de cualquier procedencia, en combinaciones impensadas anteriormente las que tienden a desligarlos de sus contextos performáticos originales. Asimismo, las crecientes posibilidades de poner a circular y trasladar sonidos mediáticamente, sobre todo mediante descargas de música vía Internet, intensifican el efecto esquizofónico. "Así, la relación música-territorio ha dejado de ser un elemento evidente (...) y se establece cada vez más desde la mediación entre lo local y lo transnacional" 14 .

Frente a esta descontextualización que afecta a las músicas locales, consideramos que el AMTCh aún mantiene una relación explícita con determinados territorios, con determinados lugares y con un pueblo determinado. Es más, la riqueza de este acervo se mantendrá en la medida que la posibilidad de acceso involucre siempre a sus orígenes geográficos y, por sobre todo, comunitarios. El álbum Pueblo en fiesta y la futura implementación de la audición remota para los registros del AMTCh de algún modo remarcarán su carácter originario y local en este contexto global de sonidos volubles. Por lo mismo es importante considerar este archivo en sus situaciones territoriales y culturales de registro y en la historia de su constitución académica y política. Como ya se ha mencionado, a medida que avanzábamos en nuestro trabajo se fueron dando reflexiones colectivas sobre el carácter patrimonial del sonido y sobre las implicancias socioculturales de las músicas locales.

\footnotetext{
11 Acuñado originalmente como "la ruptura entre un sonido original y su transmisión o reproducción electroacústica” por el músico Raymond Murray Schaffer, pasa con Steven Feld a designar esa separación entre sonoridad o música y espacio de origen.

${ }^{12}$ Ochoa 2003:36.

${ }^{13}$ Ochoa 2003:39.

${ }^{14}$ Ochoa 2003:46.
} 
Si bien el fenómeno esquizofónico implica un riesgo constante para las músicas y sonidos locales, la tecnología digital permitirá en lo futuro revertir la inaccesibilidad que ha afectado al AMTCh, dadas la obsolescencia de su soporte análogo y el encierro en el que fue mantenido durante los últimos 30 años. Ahora bien, la relevancia mundial que ha cobrado la digitalización de los registros lectográficos y audiovisuales en las perspectivas del rescate, puesta en valor y acceso, ha determinado poco a poco que, de no estar disponible un registro en dicho formato en una plataforma abierta, su propia existencia será puesta en duda. Considerando la existencia de una memoria sonora colectiva, este tipo de registros debe figurar como un recurso útil para los usos de todo público, desde especialistas, investigadores y músicos, hasta quien sea que se interese por la música, las palabras y los sonidos del Chile profundo. El disco realizado, como culminación de nuestro trabajo, fue central en concretar una gran inquietud. En términos sonoros Chile es más diverso de lo que se conoce y es muy diferente a aquellas representaciones folclóricas trasmitidas en la educación escolar y en el espectáculo. ¿Pero, a qué se debe esto? Dejando hablar a estas músicas nuestros oídos experimentan que dichas performance folclóricas distan mucho de los sonidos de estas personas arraigadas a su tierra. Con esta experiencia sonora comprobamos que la constitución de la chilenidad conllevó una homogeneización e invisibilización de las culturas popular-tradicionales del país, principalmente bajo la difusión y la pregnancia de las representaciones folclóricas. De esta forma, culturas locales que sólo se relacionaban en una existencia común bajo el Estado de Chile -Rapa Nui y la Patagonia a modo ejemplo- pasaron a formar parte de un mismo espíritu en el imaginario nacional chileno.

El AMTCh es fruto de este importante proceso de constitución identitaria. De hecho, es posible leer las claves de dicha construcción a través de las categorías y sesgos que, dado el caso, determinaron la recopilación de folclore musical, los que fueron justificados a la luz de los preceptos ideológicos y estéticos de dicho concepto de Folclore. Dentro de éstos destaca el hispanocentrismo de los referentes culturales que se buscaban ${ }^{15}$, como es el caso de los bailes chinos de la Zona Central. En sus registros se prefirieron los cantos de alféreces por sobre el sonido rajado de las flautas -el que era desestimado quizá por sonar demasiado indígena o simplemente, por que no puede ser considerado música según la estética sonora clásica. De un mismo modo, el AMTCh muestra predilección por las músicas de la religiosidad popular católica, excluyendo las músicas tradicionales de la ciudad y de las etnias del país, de las que existen muy pocas cintas frente a un grueso de folclore criollo y campesino. Es posible que tales sesgos hayan sido inconscientes o premeditados. No obstante, también es posible que haya existido una identidad oficial subyacente en estos registros cuya manifestación coincide con las formas más usuales del folclore de proyección.

Se destaca en la audición de sus registros las distintas formas de trato y de enfrentamiento de los recopiladores hacia los informantes. En el caso de los recopiladores académicos, se aprecia un interés mayor por los repertorios musicales, tendencia que desplazó la interacción con los cultores a un plano secundario o a veces inexistente.

${ }^{15}$ Torres 2005:14. 
En algunas grabaciones los recopiladores más académicos se muestran prepotentes y autoritarios ante una mala ejecución o una negativa a entregar determinado material. Por otra parte, el caso de los colaboradores del archivo -quienes, como se ha dicho, por su cuenta recopilaban su material y posteriormente lo donaban a la Universidad de Chile- existió un interés compartido por la música y por los cultores en sí, a quienes se entrevistaba en diálogos amistosos, en términos incluso halagadores y cariñosos. Los contrastes entre registros evidencian que el AMTCh no es ni homogéneo ni posee una metodología rigurosa, sino que más bien constituye una colección de grabaciones que se reunió en base a distintos criterios. Todos estos elementos también deben integrarse dentro de una perspectiva de patrimonio, mediante la cual no sólo el objeto mismo sea valorado, sino que también las acciones e ideas por las cuales dicho objeto fue generado en su propio contexto. De este modo las iniciativas de recopilación y de trabajo cultural de esa época también deben ser consideradas patrimonio. Con lo anterior se asegura una mejor comprensión de las condiciones ideológicas e históricas de la "identidad chilena” y, más aún, de la existencia de las culturas locales bajo la hegemonía de la identidad nacional.

A propósito, estas recopilaciones musicales reflejan la enorme variedad cultural que existe en Chile. En los registros perviven sonidos de enorme elocuencia, en el sentido que presentan, en la medida en que el recopilador lo registró -volvemos a los sesgos- la voz propia de los habitantes de este país, en situaciones en la que se destaca el valor comunitario de sus expresiones musicales. Mucho de esto no fue incorporado a las formas culturales oficiales. Con ello expresiones importantes del pueblo chileno fueron descartadas como representativas de la identidad nacional. Por eso pensamos que la reactivación de este archivo puede rescatar esa alteridad tan potente que ofrece el registro sonoro, mucho más rico en expresividad que, por ejemplo, el registro escrito. El énfasis puesto en la multiculturalidad y en el reconocimiento de las muchas identidades existentes en Chile, nos ha llevado a comprender que los márgenes teóricos de lo patrimonial y sus consecuencias políticas también deben ser escuchados. Previo al desarrollo de estas ideas, queremos poner en discusión ciertos conceptos centrales para nuestro artículo.

\section{Patrimonio e identidad}

Consideramos la música y los sonidos como parte de lo que UNESCO define como patrimonio cultural inmaterial, esto es "los usos, representaciones, expresiones, conocimientos y técnicas - junto con los instrumentos, objetos, artefactos y espacios culturales que les son inherentes- que las comunidades, los grupos y en algunos casos los individuos reconozcan como parte integrante de su patrimonio cultural"16. Esta definición nos parece estática. Asimismo cabe preguntarse cuál es la autoridad que reconoce y determina la naturaleza, por así decirlo, del patrimonio cultural, y cuáles

${ }^{16}$ UNESCO, Convención Para la Salvaguardia del Patrimonio Cultural Inmaterial. <http://unesdoc.unesco.org/ images/0013/001325/132540s.pdf<, visitado el 17 de julio de 2006. P. 2. 
son los usos que derivan de su decreto. Al respecto, el mismo AMTCh prueba de que muchos de los cultores registrados, que ejercían sus oficios musicales en situaciones cotidianas y de relevancia comunitaria, fueron transformados en referentes rígidos desligados de sus contextos sociales. Más aún, la gran parte de estas grabaciones quedaron reservadas casi exclusivamente al uso artístico y académico, de manera que los cultores mismos no pudieron hacer uso de sus propios registros. Todo esto hace ruido respecto a las buenas intenciones sociales del patrimonio cultural inmaterial, desde esta perspectiva.

Frente a lo anterior, consideramos que el patrimonio debe ser del uso de todos y, ante todo, de los usos de los individuos y comunidades al que pertenece. Por ello debe existir un tratamiento propicio por el cual exista una constante retroalimentación con esas comunidades. En tal sentido, preferimos la perspectiva del Consejo Andrés Bello, el que define al patrimonio como el "acervo material, inmaterial y natural del cual una sociedad determinada hace uso para enfrentar sus problemas, realizar sus sueños, para construir identidad, comunidad y futuro" ${ }^{17}$. Las expresiones culturales y los conocimientos populares, bajo esta consideración, son elementos sensibles para la consolidación de las identidades locales. Al cobrar importancia en relación a la vida de las comunidades y de sus individuos, es esencial asegurarles continuidad y proyección en el futuro. Ante la evidencia de la relación entre patrimonio cultural e identidad, los usos y definiciones sociales del patrimonio son proporcionales a la relevancia y visibilidad de una cultura tradicional heterogénea, tal cual es. En tal sentido, el concepto mismo de identidad debe ser discutido.

No podemos dejar de referirnos al texto de Jorge Larraín, Identidad chilena ${ }^{18}$, en el que el autor revisa las distintas versiones de la identidad nacional. Creemos que este ensayo ha sido un aporte para dilucidar la fibra de la chilenidad, pero nos parece aún insuficiente. Para Larraín, la identidad es un proceso de construcción que se basa en tres elementos formales constitutivos ${ }^{19}$. En función de aquello genera una catalogación de las diversas visiones de la identidad chilena a lo largo de la historia, sin cuestionar adecuadamente de dónde provienen estos rasgos culturales y sobre todo quiénes han sido los que los han definido. En nuestro trabajo hemos entendido identidad, al igual que Larraín, como un proceso de construcción social, pero creemos fundamental en esta operación destacar la acción relacional y dinámica de los sujetos, acción que permite aclarar por qué tal identidad emerge en determinado momento y por qué se reprimen y excluyen otras. "La construcción de identidad se hace en el interior de los marcos sociales que determinan la posición de determinados agen-

\footnotetext{
${ }^{17}$ Consejo Andrés Bello, Convocatoria a VI Premio CAB Somos Patrimonio. En <http://www.cab.int.co>, visitado el 7 de julio de 2006 .

${ }^{18}$ Larraín 2001.

${ }^{19}$ Concibe la identidad como un proceso social de construcción, en el que 1 - los individuos se definen a si mismos en términos de ciertas categorías compartidas; 2- el componente material, adonde los individuos proyectan sus "si mismos" o cualidades; y 3- la existencia de los otros, con los que el sujeto se define en relación a cómo es visto por los otros. Si bien estos elementos son importantes, creemos fundamental el componente relacional ausente en este análisis, por el cual los sujetos son agentes constructivos que ocupan posiciones determinadas en el campo social, existiendo disputas de poder, como lo plantea Bourdieu. En el fondo, en el proceso de construcción de identidad o de identificación se da una disputa de poder que no es reconocida por Larraín.
} 
tes y por lo tanto orientan sus representaciones y sus elecciones." ${ }^{20}$. Frederik Barth concibe la identidad como un fenómeno relacional, en el cual hay que "aprehender el fenómeno identitario en el orden de las relaciones entre los grupos sociales"21. En consecuencia la identidad es una forma de ordenamiento de los mismos grupos para establecer sus intercambios.

Las identidades diferenciadas son el resultado de la interacción entre grupos en sus procesos de diferenciación. Los sujetos se identifican, y sus identificaciones pueden ir variando, por lo que es siempre una especie de compromiso, una especie de negociación entre la autoidentidad definida por uno mismo, y una heteroidentidad definida por los otros ${ }^{22}$. Por lo mismo, lo identitario siempre se pone en juego en las luchas sociales. "El poder de identificación depende de la posición que se ocupa en el sistema de relaciones que vincula a los grupos entre sí. No todos los grupos tienen la misma autoridad para nombrar y nombrarse" 23 . Esta autoridad legítima es conferida por quienes detenten el poder, quienes imponen la definición de ellos mismos y de los otros. Por lo mismo, durante el forjamiento de los estados nacionales, la identidad se volvió un asunto significativo y delicado. Para el caso chileno, es evidente que la estructura estatal en el ejercicio de su poder ha sido tradicionalmente la que ha definido la chilenidad, y en su despliegue ha generado un remanente de identidades subalternas. Las construcciones de identidad constituyen disputas de poder, las que recrudecen en medio de conflictos sociales o bajo gobiernos autoritarios. En los últimos casos, borrar las memorias populares es benéfico para un poder impuesto. No obstante, la posesión de una identidad nacional no es en sí negativa. El tema es saber cómo se ha creado, quiénes lo han hecho y, por sobre todo, qué se ha descartado en el proceso de su construcción y cuáles han sido los costos sociales de su constitución. Durante los últimos setenta años de historia nacional, los avatares de la chilenidad configuran una escena sociocultural en la que el conflicto político ha estado siempre presente.

\section{El folclore como representación de la identidad nacional}

La idea de folclore ha sido esencial para la constitución de la identidad chilena y por lo mismo debe ser revisado. Este concepto nace en Occidente a mediados del siglo XIX como parte del discurso de la modernidad, reordenando la cultura popular y lo local en una nueva configuración política: el estado nacional. Lo "folclórico" pasó a determinar la unidad de las nacientes comunidades nacionales apelando a un supuesto espíritu preexistente a éstas, cuya expresión más pura se daba en las culturas autóctonas de cada pueblo. El folclore simboliza una relación particular con el pasado, con el transcurso de esa vida espiritual comunitaria, mediante la cual es enaltecida la tradición que lo sustenta. A su vez, el folclore determina como "tradicionales" los elementos transmitidos por ésta. ${ }^{24}$

\footnotetext{
${ }^{20}$ Cuché 1999:111.

${ }^{21}$ Cuché 1999:111.

${ }^{22}$ Cuché 1999:112.

${ }^{23}$ Cuché 1999:113.

${ }^{24}$ Ochoa 2003:90-92.
} 
En Chile, el folclore se allegó en teoría y práctica al espacio académico en formación, desde fines del siglo XIX, volcándose posteriormente en precipitados artísticos y del espectáculo. Su disposición categorial sitúa claramente el lugar de lo popular, lo tradicional o lo local, dentro de una identidad chilena. De acuerdo a su definición, el folclore es en tanto cultura, el plano en el que se relacionan sus expresiones con la vida. En otras palabras se refiere a la práctica que hacen los agentes folclóricos en sus contextos de origen, según la cohesión y fuerza social de las comunidades que los cobijan. Para el conglomerado social, el ejercicio de estas prácticas proviene y se sostiene en la tradición, y sólo en ella dichas expresiones se vuelven representativas de un espíritu comunitario ${ }^{25}$. Las perspectivas y métodos analíticos que se ocupan del plano folclore-vida constituyen la ciencia folclórica. Sus estudios proveen un conocimiento efectivo sobre aquellas "supervivencias inmediatas" de las culturas locales que perduran en el medio sociocultural contemporáneo, en el que las fuerzas de desarrollo global representaban una persistente amenaza de desaparición para estas formas tradicionales ${ }^{26}$. La definición anterior remite a una noción más positivista de estudio folclórico, sin duda, consecuente con su índole académica, la que dista bastante del concepto temprano, que en Europa decimonónica estuvo inspirado por un espíritu romántico, el que le imprimió un carácter más emotivo y reflexivo.

A partir de la cultura folclórica y de su síntesis científica, el desarrollo de esta ciencia determinó un plano activo, el de la "proyección folclórica". Este concepto corresponde a la “(...) manifestación producida fuera de su ambiente geográfico y cultural, por obra de personas determinadas (...) que se inspiran en la realidad folklórica cuyo estilo, formas, o carácter trasuntan y reelaboran en sus obras e interpretaciones, destinadas al público en general, preferentemente urbano, al cual se transmiten por medios mecánicos e institucionalizados, propios de la civilización vigente en el momento que se considere (...)"27. Este es el plano en el que los derivados eruditos son procesados interpretativamente para su exhibición a un público que no tiene acceso directo a sus expresiones puras, generalmente el público urbano. Las actividades efectuadas en este plano son realizadas por los intérpretes folclóricos, quienes se diferencian considerablemente de los cultores naturales, por realizar su performance fuera de los ambientes originarios, y con otros criterios artísticos que transforman el marco estético de las músicas tradicionales, regidos por otros sistemas de representaciones, gustos y sonoridades. A pesar de la diferenciación que aquí se evidencia, las categorizaciones no impiden que en una misma persona confluyan cultor e intérprete, tratándose sólo de un tema contextual.

En general, la mirada del folclore es una interpretación en sí de la realidad, que ordena y clasifica sus fenómenos, en consideración a una identidad nacional y dentro de un marco en el que predominan las ópticas disciplinarias. Opera según criterios estéticos - que buscan y fijan la "pureza" en lo que aún no se ha mezclado ni transformado, y que así debe resguardarse, junto a criterios sociales - que se refieren usualmente a la cultura vernácula de las clases bajas, preferentemente orales. Además

\footnotetext{
${ }^{25}$ Dannemann 1975:24.

${ }^{26}$ Dannemann 1975:18-19.

${ }^{27}$ Dannemann 1975:25.
} 
opera en la ruralidad- criterios políticos - que reconocen como lo propio de un territorio y de una población bajo la autoridad de un estado determinado- y según criterios temporales, que juzgan folclórico aquello que, no cambiando nunca, se mantiene siempre igual a sí mismo, es decir, vendría a ser una esencia despojada de historicidad.

La complementación cultural del proyecto desarrollista se efectuó en el plano de las bellas artes y la educación, con un criterio mediante el cual la homologación de la cultura ciudadana de Chile, con una universal de tipo eurocentrista, era imperativo. Pero también se efectuó en el plano de lo local, en el que el folclore cobró una importancia central, sobre todo para el quehacer de los artistas cultos y de espectáculos que se involucraron con los desafíos identitarios de la nación. En una medida similar, esta categoría cobró relevancia dentro del ámbito académico, particularmente tras la implementación de una nueva institucionalidad cultural para la Universidad de Chile, a partir de la década de 1940. Con variaciones en el trabajo de los investigadores e intérpretes, las actividades folclóricas se llevaron a cabo de forma aunada, basada en un reconocimiento general de la estructura categorial descrita más arriba. Siguiendo a estas categorizaciones, las primeras actividades folclóricas consistieron en "desenterrar", observar y conservar las expresiones del folclore en sus contextos, lo que en la orilla musical se llevó a cabo con guitarra y anotaciones, o cuando existían mejores medios, con máquina grabadora y otros recursos tecnológicos.

Esta labor garantizaba el atesoramiento de la música del pueblo chileno, cuyo develamiento llevó a cierta folclorista a afirmar: "cuando me iba a imaginar yo que, al salir a recopilar mi primera canción un día del año ' 53 a la comuna de Barrancas, iba a aprender que Chile es el mejor libro de folklore que se haya escrito"28. Probablemente esta haya sido la impresión para muchos de los recopiladores que se enamoraron de la diversidad y riqueza sonora que encontraron durante sus excursiones al Chile profundo. No obstante, el gesto científico predominó sobre el afecto, inculcando a estas actividades más rigurosidad y efectividad que empatía para con los cultores y con su arte.

A partir de los estudios científicos, y posteriormente gracias al trabajo de los folcloristas, las culturas tradicionales fueron incorporadas dentro de la cultura ciudadana de la época, aportando una mirada hacia el interior del país que podría compensar la adopción de referentes cosmopolitas, tanto en la cultura como en los procesos productivos y en los hábitos de los chilenos. Las culturas locales quedaron organizadas en una nueva perspectiva cultural, según claves cultas y cosmopolitas, las que seleccionaron algunos elementos a partir de la diversidad local, dibujando sobre ésta una imagen más homogénea y ordenada ${ }^{29}$. Las segregaciones y ajustes aplicados al espectro folclórico favorecerían la provechosa inculcación de una identidad nacional hegemónica. Esta ponderaba valores orientados a la aceptación de un rol social ciudadano para los habitantes del país, además del reconocimiento de la autoridad estatal, cuyo carácter democrático debía fortalecerse, como culminación de un compromiso con Chile y con su proyecto desarrollista. Lo folclórico señala, por un lado, la legitimidad

\footnotetext{
${ }^{28}$ Parra 1957.

${ }^{29}$ Chatterjee 2000:128.
} 
cultural y simbólica del estado, como agente principal de identificación, y por el otro, la concreción de un espíritu nacional en construcción.

Podríamos decir que estamos ante una alegoría de la nacionalidad ${ }^{30}$. Lo folclórico conforma una escena en la que figuran los personajes y las situaciones "ideales" de una chilenidad "ideal", según cánones implícitos que favorecen un perfil y ocultan otros que no aparecen en la representación oficial. Como ejemplo, en la representación folclórica a la que se hizo referencia anteriormente han predominado los elementos hispano-mestizos de las culturas locales. Por lo tanto su ambientación predilecta ha sido el Valle Central o todo espacio en el que se pueda identificar algún elemento para este canon folclórico chileno.

La difusión de los estudios folclóricos nacionales se realizó en los medios escolares y académicos, acorde a las necesidades de crear una conciencia identitaria para una ciudadanía en trance de cambios históricos radicales. Por sobre todo, esta identidad debía ser "proyectada" en los espacios en los que ya no pervivían estas manifestaciones autóctonas, de modo que los públicos eminentemente urbanos, a lo largo del país, pudiesen dar cuenta de los componentes basales de su cultura nacional. El folclore de proyección operó entonces como la imperiosa mediación, derivada del conocimiento académico y del acercamiento a los contextos de origen, entre las expresiones aún vivas del folclore y un público nacional, mayoritario, que las había perdido y que necesitaba recuperarlas como referente íntimo de su chilenidad. Así, desde la década de 1950 el folclore de proyección creció con energía bajo el alero de intérpretes tales como Margot Loyola y los Conjuntos Cuncumén y Millaray, quienes también desarrollaron una importante actividad de recopilación que tuvo como fin el engrosamiento de su repertorio musical y coreográfico. El máximo cometido de estas iniciativas era, según la idea de la proyección, mostrar las manifestaciones del folclore, de modo que el montaje escénico pasó de ser el medio objetivo para llevarlos al público. El círculo de mediaciones folclóricas se cierra entonces con la proyección, la que implica una interpretación que "trasunta" esas expresiones originales en otro contexto en el cual, para decirlo críticamente, ya no domina la identidad comunitaria, sino la nacional. La metáfora escénica anterior cobra entonces pleno sentido.

Se puede apreciar que, hablar de folclore es complicado, más aún si lo hacemos resaltando la conflictividad inherente a la conformación de identidades y a sus representaciones en la cultura. Para nosotros es esencial aclarar que, para las músicas locales, lo folclórico dista de ser un testimonio en primera persona de la totalidad de componentes sociales del pueblo chileno. Esto no implica desmerecer el enorme valor que puede representar el folclore como estilo de la historia musical chilena. Pero si nuestra intención ha sido reivindicar una voz popular, local o tradicional, como quiera llamársele, o insistir en una idea más dinámica de identidad, ésto necesariamente implica la revisión crítica de dicha categoría y de sus derivados más típicos. Entendemos que, en el plano de las representaciones de la cultura nacional, el folclore alude a una adscripción política oficial. Es una categoría discriminatoria que

${ }^{30}$ Aquí nos referimos a la clásica definición de Benedict Anderson, por la cual nación es "una comunidad política imaginada como inherentemente limitada y soberana”. Cf. Anderson 1993:23. 
da cuenta alegóricamente de un ideal de ciudadano, en el que lo mestizo, lo indígena, lo inculto y lo primitivo -según los valores modernos- sólo caben de una forma tal que su participación depende de su subordinación al proyecto nacional implícito en lo folclórico.

Este aspecto político es fundamental para entender la conformación histórica del AMTCh. La mirada científica estableció roles estrictos en relaciones sociales objetivadas, es decir, la hegemonía del investigador/recopilador, en el grueso de los casos, sólo reconoció la importancia de los cultores en tanto informantes, en tanto fuentes de una información que, al ser entregada, descartaba la participación de estas personas en la construcción de un conocimiento posterior. En forma similar, están las pretensiones cultas del folclore de proyección, que comúnmente se traducen en proyectos artísticos incubados en el canon de las "bellas artes". Suponían por lo tanto una filtración estética que perfeccionaría aquellos detalles desagradables de las manifestaciones puras, las voces e instrumentos destemplados, la mala dicción, la desafinación, y otros detalles que no sólo son válidos por sí mismos, sino que involucran una perspectiva estética popular incomprendida desde este "criollismo culto".

Desde esa perspectiva se entendería la queja expresada por don Fernando González Marabolí: "el músico y el poeta culto se creen con el derecho de innovar o arreglar la instrumentación, las entonaciones y el canto del pueblo, porque lo consideran malo debido a que éste no sabe y le falta mucho. Pero, ¿qué es lo que le falta, ser más europeo o norteamericano? El chileno vive orgulloso de sus tradiciones: las entiende y las respeta. Ellos, sin entenderlas, se toman el derecho a modificarlas" 31 . El folclore de proyección resume el complejo de mediaciones y representaciones, científicas y artísticas, que ha penado sobre las culturas locales chilenas. Este complejo se correspondería con la falta de protagonismo que estas culturas han tenido dentro del proyecto nacional y de su cultura oficial. En relación a lo mismo, el folclore alude a una porción de la realidad nacional cruzada por desigualdades en todos sus ámbitos, las que fueron anuladas en la representación artística resultante. Nosotros entendemos este fenómeno como una transformación de lo tradicional-local-popular a formas cultas y oficiales, mediante correcciones, en un modo que puede corroborarse, por ejemplo, mediante la audición comparativa del material de campo conservado en este archivo y de sus interpretaciones folclóricas consecutivas.

\section{Conclusiones}

En los casi 70 años que han transcurrido desde la conformación institucional del AMTCh, las formas de la nacionalidad chilena han transmutado sucesivas veces, causando cambios profundos en la apreciación general sobre el patrimonio colectivo, y en un nivel más profundo, en la identidad nacional de nuestros días. Los avatares de la mentada globalización han llevado a una porción de los actuales trabajadores de la cultura a volver la mirada hacia la cultura tradicional chilena, como un modo, quizás, de aferrarse a algo propio dentro de la amplísima oferta de modas culturales

\footnotetext{
${ }^{31}$ González Marabolí 1994:143.
} 
globalizadas. Sin ser nuestra intención generar un referente nacionalista en nuestro acercamiento a las músicas locales-tradicionales de Chile, hemos comprobado una diversidad de sonidos y estilos que, además de deslumbrarnos, nos ha llevado a preguntarnos sobre el desconocimiento general que existe sobre estas músicas dentro del gran público.

Una primera respuesta, aunque tentativa, aludió a la tendencia muy común en la gente a relacionar el folclore con la cultura oficial de la dictadura militar, de un modo similar a como en general la Nueva Canción Chilena es relacionada con la vida cultural de la Unidad Popular - esta última, relación fundada y correcta, por cierto. La proscripción total de amplias áreas de la producción intelectual y artística chilena durante los años 1970 y 1980 también alcanzó a las músicas tradicionales-populares desmarcadas del ámbito folclórico, como es el caso del llamado "folclore urbano", la Cueca Brava, la que durante la década de 1960 y hasta 1973 hizo su ingreso a la industria discográfica. Así pudo ser como el folclore, según una identidad nacional fija de esta forma durante las décadas posteriores al golpe militar, se volvió una herramienta eficaz para simbolizar una chilenidad aún más esclerotizada, una chilenidad que debía alegorizar el imperativo de adscribirse sin reservas a la autoridad del estado chileno -es decir, de la junta militar- y a su modelo de ciudadanía. No es raro que el 18 de septiembre de 1979, mediante decreto ley de la república, la cueca haya sido declarada "danza nacional" de Chile y emblema nacional, al extremo que, de ser mal bailada se podría incurrir en sanciones por ofensa a la Patria.

Los recurrentes juicios en torno al "folclore milico" o al "folclore de postal" exacerbado durante la dictadura, bien podrían basarse en estas suposiciones y hechos concretos. De todas maneras, las identidades nacionales desarrollistas y cosmopolitas -o frontalmente fascistas- dependen en algún grado de la invisibilidad de las diversas identidades subalternas que, en nuestro caso, son comprobables en un amplio espectro sonoro y musical en Chile. Por su parte, la visibilidad de estas identidades subalternas y una justa valoración, dependen en alto grado del entender, en primer lugar, cuáles han sido los procesos socio-históricos por los cuales han sido invisibilizadas y proscritas. En segundo lugar, dependen de una valoración adecuada de sus bienes culturales y de los modos en que deben ser manejados, de manera que los cultores y sus comunidades sean también valorados, reconocidos y respetados.

Por lo tanto, y a la luz de toda esta exposición, se hace evidente la necesidad de enfrentar el problema del patrimonio como un problema entre personas y comunidades. En tal sentido, toda iniciativa patrimonial debe considerar sus implicancias políticas y socio-históricas para la configuración de identidades, es decir, debe enfocarse hacia una democratización del patrimonio, para hacer de éste una herramienta social que empodere a las mismas comunidades y personas, mejorando así sus vidas y proyectándolas al futuro. Asimismo, confrontando el contexto de desarrollo histórico del AMTCh, y su proyecto cultural implícito, con las acciones y perspectivas actuales de patrimonio en Chile, surgen las preguntas: ¿existe, tras los márgenes conceptuales y las políticas públicas del actual estado chileno, un proyecto cultural? Si fuera así, ¿cuál es?, ¿qué busca? Tras estas interrogantes, lo único que queda como convicción es la necesidad de ampliar la participación de las diversas comunidades de la sociedad chilena -entiéndase, desde los pueblos originarios hasta los gremios de profesores, 
estudiantes y trabajadores de la cultura en general- en la construcción de referentes culturales que efectivamente refuercen sus identidades particulares y sus respectivos sentidos de pertenencia, en programas de desarrollo sostenidos en el tiempo y con financiamiento directo. No obstante la ampliación del concepto de patrimonio por parte del CNCA, entrevemos en sus políticas un cierto gesto cosista, por el cual se desarrollan productos sólo aptos para el intercambio dentro de un ámbito globalizado de consumo cultural, en el que se descartan sus usos sociales en sus contextos cotidianos. Las culturas locales no sólo deben transformarse en productos de exportación no-tradicional. Por lo mismo, se hace necesario transparentar los criterios ideológicos que han regido las políticas culturales públicas a lo largo de la historia de Chile.

Este develamiento del AMTCh nos ha permitido demostrar los modos en que se ha construido la chilenidad desde una sensibilidad tan particular como es el sonido, sensibilidad que no ha sido incorporada adecuadamente en los trabajos de las ciencias sociales y de las humanidades en Chile. Al respecto, cabe señalar que, en contextos más amplios, el sonido y las músicas acompañan a diario la vida de las personas, teniendo una existencia real y transversal en términos etarios, de clase y de género, por mencionar algunos solamente. Lo esencial en el futuro será que este tipo de archivos continuen su labor en soportes que favorezcan su difusión y su uso. Una puesta en valor que en verdad les otorgue calidad de patrimonio público implicará, por lo tanto, un cambio radical en la idea de archivo audiovisual. Para nosotros ha sido primordial entender que la imagen y el sonido también son parte basal de la memoria humana, toda vez que lo audible enmarca y acompaña las vidas individuales y sociales. Al eliminarse lo audible se lleva con él parte de lo que define nuestras vidas. La tecnología ha posibilitado congelar recuerdos en imagen-sonido, recuerdos que siempre podrán volver si el registro está a la mano para la rememoración y la relectura.

\section{BIBLIOGRAFÍA}

Anderson, Benedict.

1993 Comunidad imaginada. Reflexiones sobre el origen y la definición del nacionalismo. México: Fondo de Cultura Económica.

Chatterjee, Partha.

2000 "El nacionalismo como problema en la historia de las ideas políticas", La invención de la nación. Lecturas de la identidad de Herder a Homi Bhabha. Álvaro Fernández Bravo (editor). Buenos Aires: Ediciones Manantial, pp. 123-164.

Consejo Andrés Bello

2006 Convocatoria a VI Premio CAB Somos Patrimonio. En http://www.cab.int.co, visitado el 7 de julio de 2006.

Cuché, Denys

1999 La noción de cultura en las ciencias sociales. Buenos Aires: Ediciones Nueva Visión. 
Dannemann, Manuel

1975 "Teoría folklórica. Planteamientos críticos y proposiciones básicas", Teorias del folklore en América Latina. Manuel Dannemann (editor). Caracas: INIDEF/CONAC, pp.11-43.

2007 "Pueblo en fiesta. Músicas tradicionales de Chile. CD". Reseña, RMCh, LXI/208 (julio-diciembre), pp. 101-102.

GonzÁlez Marabolí, Fernando

1994 "El canto a la daira o cueca tradicional", Chilena o cueca tradicional de acuerdo con las enseñanzas de Fernando González Marabolí. Samuel Claro Valdés (editor). Santiago: Ediciones Universidad Católica de Chile, pp. 72-189.

LARRAÍN, JORGE

2001 Identidad chilena. Santiago de Chile: LOM Ediciones.

OCHOA, ANA María

2003 Músicas locales en tiempos de globalización. Buenos Aires: Grupo Editorial Norma.

PARRa, Violeta

1957 “La cueca presentada por Violeta Parra”, El folklore de Chile. Volumen III. Santiago: EMI Odeón Chilena, LDC-36038.

Rojo, Grínor, Alicia Salomone y Claudia Zapata

2003 Poscolonialidad y Nación. Santiago de Chile: LOM Ediciones.

TORRES, RODRIGO

2005 Aires tradicionales y folklóricos de Chile, 1944. Edición de Rodrigo Torres. Santiago: Universidad de Chile, Facultad de Artes, Centro de Documentación e Investigación Musical.

UNESCO

2006 Convención para la salvaguardia del patrimonio cultural inmaterial.

$<$ http://unesdoc.unesco.org/images/0013/001325/132540s.pdf $<$, visitado el 17 de julio de 2006. 